\title{
Combined Transcavernous and Kawase's Approach for Gross Total Resection of a Cavernous Sinus Meningioma
}

\author{
Walid Elshamy ${ }^{1,2}$ Burak Ozaydin ${ }^{1} \quad$ G. Mark Pyle ${ }^{3}$ Mustafa K. Baskaya ${ }^{4}$
}

${ }^{1}$ Department of Neurological Surgery, University of Wisconsin-Madison School of Medicine and Public Health, Madison, Wisconsin, United States

2 Department of Neurological Surgery, Ain Shams University, Faculty of Medicine, Cairo, Egypt

${ }^{3}$ Department of Surgery, Division of Otolaryngology-Head and Neck Surgery, Section of Otology/Neurotology, University of WisconsinMadison School of Medicine and Public Health, Madison, Wisconsin, United States

${ }^{4}$ Department of Neurological Surgery, University of Wisconsin-Madison School of Medicine and Public Health, Madison, Wisconsin, United States
Address for correspondence Mustafa K. Baskaya, MD, Department of Neurological Surgery, University of Wisconsin-Madison, 600 Highland Avenue, CSC K8/828, Madison, WI 53792, United States (e-mail: baskaya@neurosurgery.wisc.edu).

J Neurol Surg B Skull Base 2022;83(suppl S3):e603-e605.

Conflict of Interest

None declared.

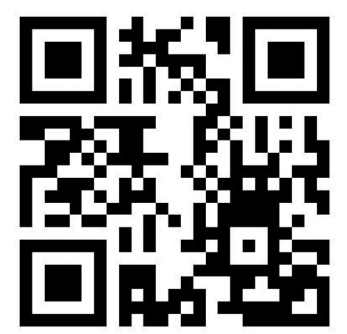

received

April 30, 2020

accepted

October 18, 2020

published online

April 8, 2021
Microsurgery of cavernous sinus (CS) lesions is generally considered to be associated with a high rate of morbidity and cranial nerve deficits. The success for surgical removal of CS meningiomas is debatable and achieving a good functional outcome with preservation of the cranial nerves is the goal. Surgery of these lesions is challenging, recurrence rates are high, and therapeutic strategies remain controversial. In this video, we present a case of a CS meningioma that extended to Meckel's cave and the posterior fossa in a 46-year-old woman with history of a left-sided cerebellopontine angle World Health Organization (WHO) grade-I meningioma with extension to the left CS. Seven years ago, she had a microsurgical resection of a Cerebellopontine angle (CPA) meningioma. She later received radiotherapy for the slowly growing meningioma

www.thieme.com/skullbasevideos

www.thieme.com/jnlsbvideos

DOI https://doi.org/ 10.1055/s-0041-1725025. ISSN 2193-6331.

\footnotetext{
(C) 2021. The Author(s).

This is an open access article published by Thieme under the terms of the Creative Commons Attribution-NonDerivative-NonCommercial-License, permitting copying and reproduction so long as the original work is given appropriate credit. Contents may not be used for commercial purposes, or adapted, remixed, transformed or built upon. (https://creativecommons.org/ licenses/by-nc-nd/4.0/) Georg Thieme Verlag KG, Rüdigerstraße 14, 70469 Stuttgart, Germany
} 

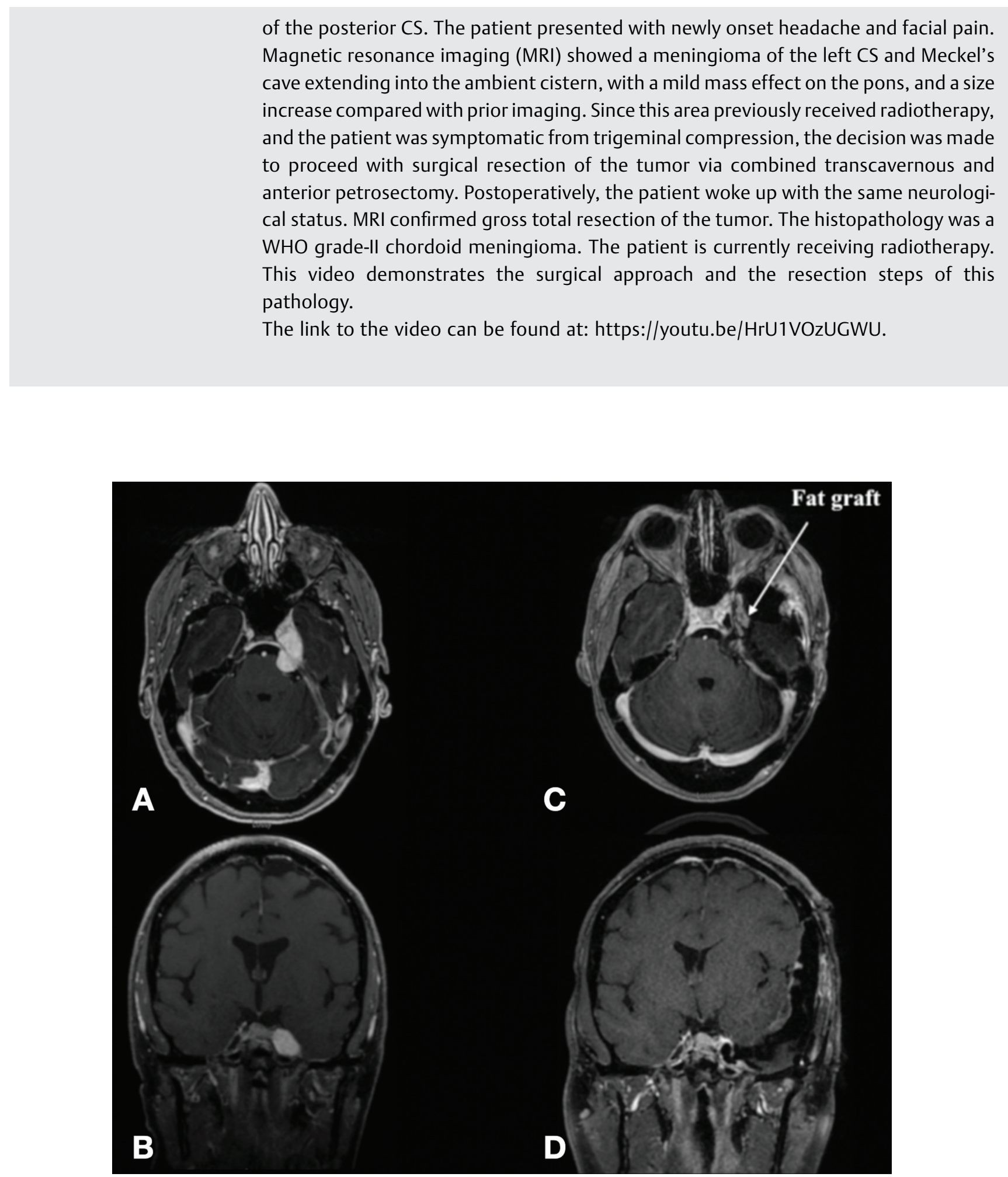

Fig. 1 Preoperative axial (A) and coronal (B) T1-weighted MRI with contrast shows left-sided homogenously enhancing cavernous sinus lesion with an extension to the posterior fossa. Postoperative axial (C) and coronal (D) T1-weighted MRI with contrast shows postoperative changes and gross total resection of the lesion from the cavernous sinus with packed fat graft (arrow). MRI, magnetic resonance imaging. 


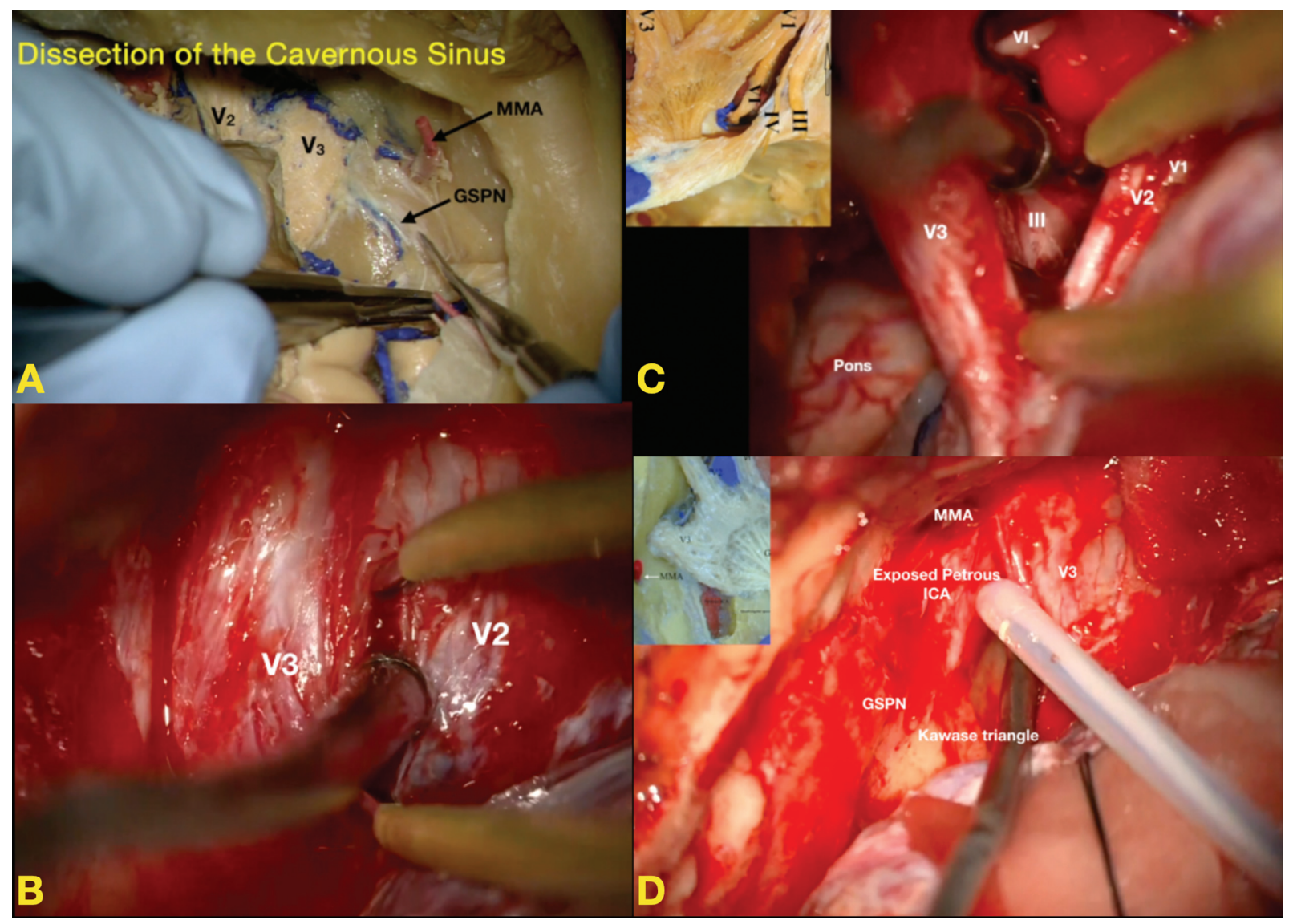

Fig. 2 Cadaveric and intraoperative photomicrographs. (A) Cadaveric dissection of the cavernous sinus shows the middle meningeal artery (MMA), V2, and V3 branches of the trigeminal nerve, and greater superficial petrosal nerve (GSPN). (B) Intraoperative photomicrograph showing the incision of the membranous layer of the cavernous sinus dura between the V2 and V3 branches of the trigeminal nerve. (C) Intraoperative image of the left cavernous sinus after tumor excision shows the branches of the trigeminal nerve (V1, V2, and V3), oculomotor nerve (III), and the abducens nerve $(\mathrm{VI})$ in the lateral wall of the cavernous sinus. Inset shows the cadaveric dissection of the same region. (D) Intraoperative image of the middle cranial fossa with an inset of cadaveric picture of the same region. Note the exposed petrous internal carotid artery (ICA), and the Kawase's triangle bounded by the petrous ridge, GSPN, and the V3 branch of the trigeminal nerve. MMA, middle meningeal artery. 